\title{
X-ray fluorescence spectroscopy and Monte Carlo characterization of a unique nuragic artifact (Sardinia, Italy) is
}

\author{
Antonio Brunetti ${ }^{\mathrm{a}, *}$, Anna Depalmas ${ }^{\mathrm{b}}$, Francesco di Gennaro ${ }^{\mathrm{c}}$, Alessandra Serges ${ }^{\mathrm{c}}$, Nicola Schiavon ${ }^{\mathrm{d}}$ \\ a Dipartimento Polcoming, Università di Sassari, Italy \\ b Dipartimento di Storia, Scienze dell'uomo e della Formazione, Università di Sassari, Italy \\ c Soprintendenza Museo Nazionale Preistorico Etnografico "Luigi Pigorini", Rome, Italy \\ ${ }^{\mathrm{d}}$ Hercules Laboratory for the Study and Conservation of Cultural Heritage, University of Évora, Portugal
}

\section{A R T I C L E I N F O}

\section{Article history:}

Received 15 October 2015

21 January 2016

Accepted 27 April 2016

Available online 30 April 2016

\section{Keywords:}

XRF

NDT

Simulation

Cultural heritage

\begin{abstract}
A B S T R A C T
The chemical composition of a unique bronze artifact known as the "Cesta" ("Basket") belonging to the ancient Nuragic civilization of the Island of Sardinia, Italy has been analyzed by combining X-ray Fluorescence Spectroscopy (XRF) with Monte Carlo simulations using the XRMC code. The "Cesta" had been discovered probably in the XVIII century with the first graphic representation reported around 1761. In a later draft (dated 1764), the basket has been depicted as being carried upside-down on the shoulder of a large bronze warrior Barthélemy (1761), Pinza (1901), Winckelmann (1776). The two pictorial representations differed only by the presence of handles in the most recent one. XRF measurements revealed that the handles of the object are composed by brass while the other parts are composed by bronze suggesting the handles as being a later addition to the original object. The artifact is covered at its surface by a fairly thick corrosion patina. In order to determine the bronze bulk composition without the need for removing the outer patina, the artifact has been modeled as a two layer object in Monte Carlo simulations.
\end{abstract}

(c) 2016 Elsevier B.V. All rights reserved.

\section{Introduction}

The Nuragic civilization thrived in the island of Sardinia, Italy, from the Middle Bronze Age up to the VI century BC, leaving an important legacy of bronze artifacts to the European cultural heritage. Indeed, an impressive variety of bronze objects depicting several subjects (such as boats, ritual and battle swords as well as human or animal figures, the latter better known as bronzetti) have been discovered, some unique from a typological point of view. One of these rarities is represented by the so-called "La Cesta (The Basket)" a basket-shaped bronze which is actually the most peculiar part of one of the largest human statuette ever discovered in Sardinia (now part of the collection of pre-historic bronzes stored in the Pigorini's museum in Rome (inv. 25528.001; Fig. 1). It consists of a hollow elliptical object with straight long and curved short sides; the walls are composed of parallel ledges bands arranged in slightly protruding on each other. The top is constituted by a sort of extrados convex cover, with four protruding elements arranged to produce a cross. On the opposite side, corresponding to the hollow part, there are two parallel rod-shaped elements, broken at both ends.

\footnotetext{
is Selected Paper from the Colloquium Spectroscopicum Internationale XXXIX (CSI 2015),

Figueira da Foz, Portugal, 30 August - 3 September 2015.

* Corresponding author.

E-mail address: brunetti@uniss.it (A. Brunetti).
}

Between the two opposite sides of the object, two half rings are fixed to act as a bridge.

The exact circumstances regarding the discovery of both statuette and basket in Sardinia are still unclear, although their dating as one of the most ancient Nuragic objects ever discovered is widely accepted amongst archeologists. What it seems certain is that the two pieces were originally separated and had been joined to each other only after their transport to the Museo Nazionale Romano, Italy with the basket somewhat strangely positioned upside-down on the statuette's head as resembling a hat. The first pictorial representation of this unique object was published by Barthélemy in 1761 [1] while a second one was published by Winckelmann in 1764 [2]. Another sketch (around 1900) reproduces the human statuette while it was still stored at the Kirker museum in Rome. with the basket already positioned on its head (see Fig. 1) The "strange" positioning of the basket had been interpreted by Giovanni Pinza (1901, c. 200) [3] as it representing a food container placed in such a strange manner because the warrior represented by the statuette, have had to tight to his shoulder the shafts of a cart (also hosted at the Pigorini museum). However, this explanation did not take in account the previous two drafts where the basket was indeed absent. Thus, from these sources it is possible to establish that the basket had been added between 1764 and 1900. The current study reports for the first time XRF analyses on this intriguing artifact. Due to its non destructive nature, $\mathrm{X}$-Ray Fluorescence Spectroscopy has become a very commonly used analytical technique in Cultural Heritage 


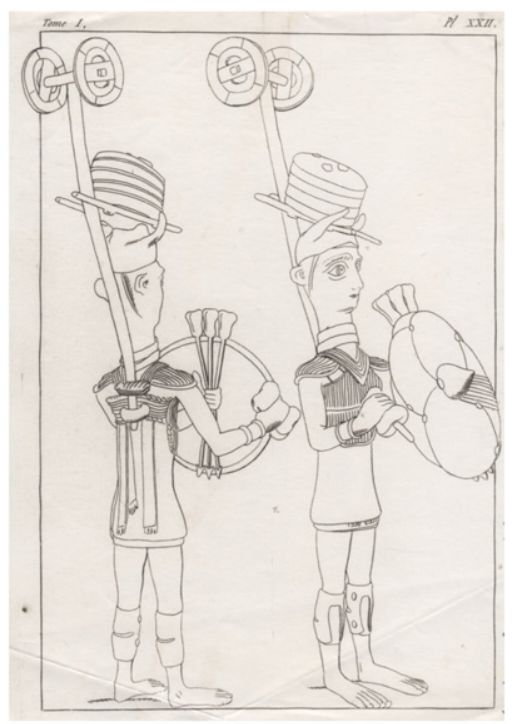

(a)

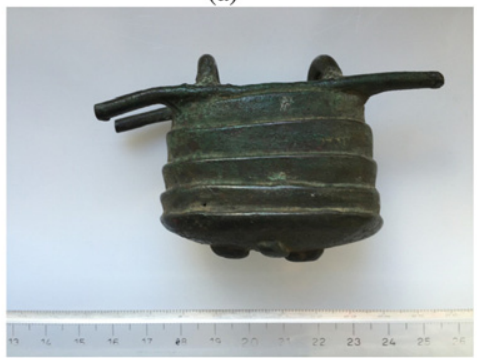

(b)

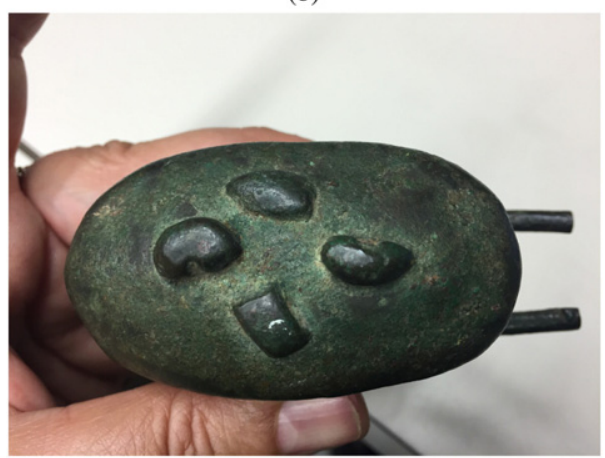

(c)

Fig. 1. Nuragic warrior. a) sketch with basket; basket lateral (b) and bottom (c) views (major axis of 8.25 , minor axis of $4.73 \mathrm{~cm}$ ).

Conservation Science [4-8]. In XRF Spectroscopy quantitative analyses, the most common approach is to extract the peak area and use a quantification algorithm such as Fundamental Parameter Method (FPM) to determine elemental concentration, [9-12]. In this paper, we use a different, innovative approach where Monte Carlo simulation is used instead of FPM for quantification allowing a better determination of both relative concentrations and sample structure. With this methodological approach complex structures such as rough surfaces can be also analyzed and simulated. XRF measurements were carried out by a custom made portable XRF system, an essential setup when analyzing precious samples which cannot be removed from their museum environment.

\section{Methods}

The adopted analytical protocol is based on the integration of XRF measurements and Monte Carlo simulations. In XRF spectroscopy, different approaches are possible according to the type of X-Ray excitation used. Some authors use monochromatic or almost monochromatic $\mathrm{X}$-Rays which facilitate peak extraction and the determination of the elemental composition of the sample, due to the background contribution being almost negligible in these cases [13-15]. However, a significant part of information can also be extracted from the spectrum background region such as it is the case, for example, when dealing with the contribution to the spectrum of protective layers (often applied by restorers to the surface of ancient metal objects) which is essentially stored in the background region. Of course the thickness and composition of the protective layer is not important by itself, but its presence may still alter the spectrum and influence estimate of bronze bulk composition. For this reason, our approach requires unfiltered X-Ray excitation. Monte Carlo technique is based on a probabilistic simulation of the phenomenon. In our particular case, we are simulating the interaction of X-Rays with matter. A virtual array of photons is probabilistically generated and their interaction with the sample is determined also on a probabilistic basis biased by the cross sections. This approach requires a good random generation as well as an accurate description of the sample structure and composition. The geometry of the analytical set-up needs also to be modeled accurately. Standard Monte Carlo methods and codes require long simulation times, in the order of several hours up to few days, in order to produce a simulated measurement with good statistical control. For these reasons, these codes are generally not applicable to real experiments. However, a number of fast Monte Carlo codes have been developed for this specific application. They are based on the so-called variance reduction techniques which allow to reduce the simulation time down to few minutes, such as is the case with the XMI-SIMS and XRMC code packages [16-20]. In this paper we use the XRMC code. It is based on a continuously updated X-Ray database called Xraylib [21-22]. XRMC is able to simulate any kind of X-Ray analysis at energy up to $100 \mathrm{keV}$. Moreover, it is also able to simulate rough, irregular, surfaces which are often found in cultural heritage samples [22-24].

The simulation approach applied here for sample composition and structure estimate is based on a set of measurements of good quality in terms of statistic and a set of simulations. The composition and structure are adapted in an effort to minimize any spectrum difference between measured and simulated spectra. The quality of the Monte Carlo simulation is initially determined by visually comparing real and simulated spectra and then refined by applying a chi-squared test. The capability of the XRMC code to simulate rough surface has been used for choosing the optimal experimental setup, with the aim of reducing to a minimum the influence of roughness. The experimental setup is based on a X-Ray tube (Mini-X by Amptek, silver anode) operating at $40 \mathrm{kV}, 5-20 \mu \mathrm{A}$ and a 1-2-3 SDD (Amptek). The unfiltered X-Ray spectrum is collimated to $1 \mathrm{~mm}$ in diameter, while no collimation is applied on the detector side. In the real experiment, the X-Ray tube was tilted from $20^{\circ}$ to $40^{\circ}$, while the detector is placed at about $0^{\circ}$ with respect to the plane described by the detector and the X-Ray tube (see Fig. 2). When feasible, the X-Ray tube was also also placed orthogonally with respect to the sample surface as geometrical set-up can be simulated by the Monte Carlo. The Monte Carlo code, for the measurements reported here, was run on a laptop (Intel® Centrino i3). Each measurement lasted about $4 \mathrm{~min}$, while each Monte Carlo simulation required about 2 min.

\section{Results and discussion}

The object analyzed here is very complex, being formed by a basket with two handles and four shafts. Measurements were performed on several selected areas. For Montecarlo simulation, the point of analysis on the body of the basket was geometrically regarded as a flat surface, while both handles and shafts were considered as cylindrically shaped areas. 


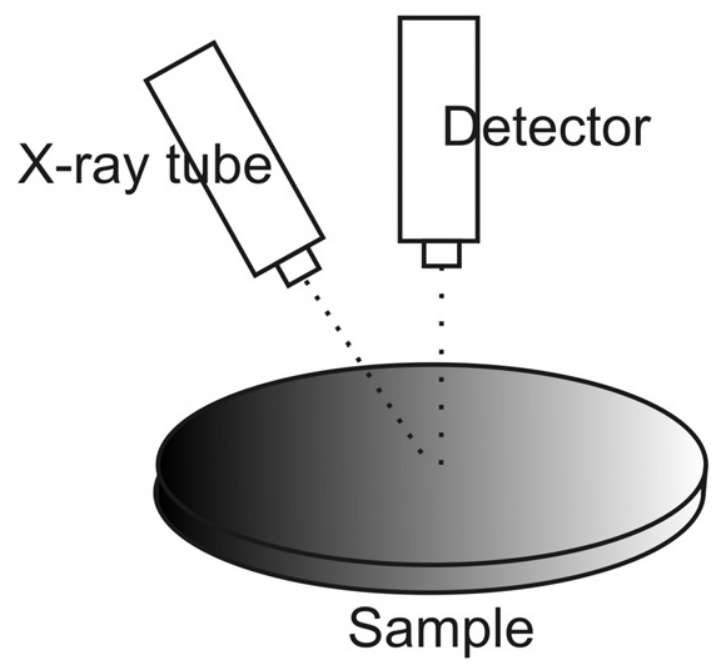

Fig. 2. Sketch of the experimental setup. The detector and the X-ray tube are placed on a plane orthogonal to the surface of the sample. The detector is placed on the vertical with respect to the surface of the sample and the detector forms with it an angle of $20^{\circ}-40^{\circ}$.

In Fig. 3a, the experimental spectrum of a spot at the bottom of the sample is depicted superimposed to the simulation spectrum. In this case, the sample is modeled as a flat multilayer surface formed by two

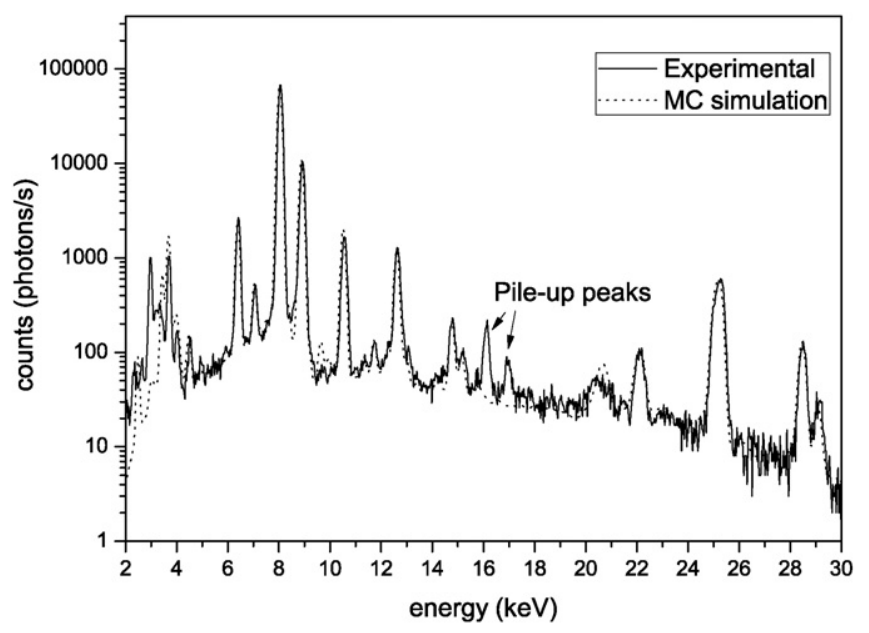

a)

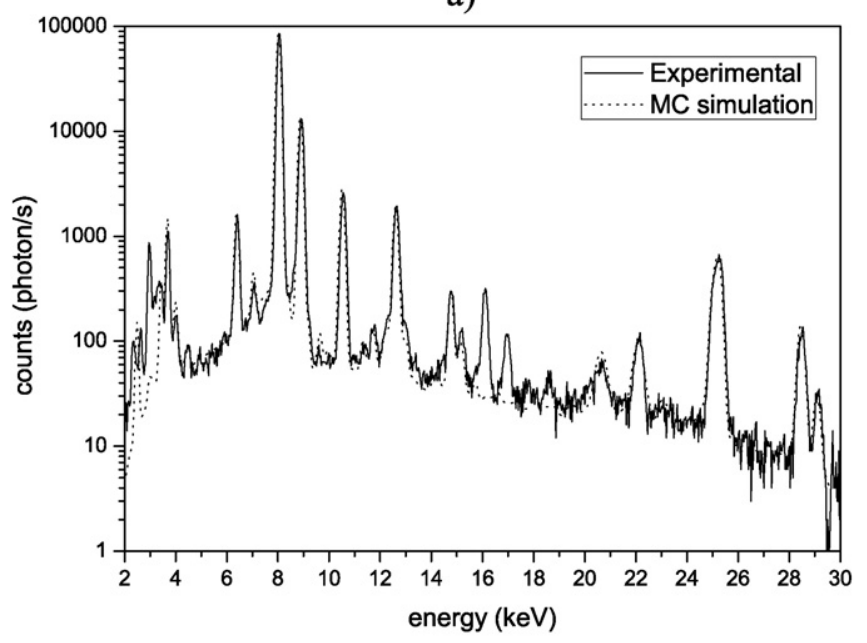

b)

Fig. 3. Experimental and simulated spectra of the basket. a) bottom and b) lateral spots.

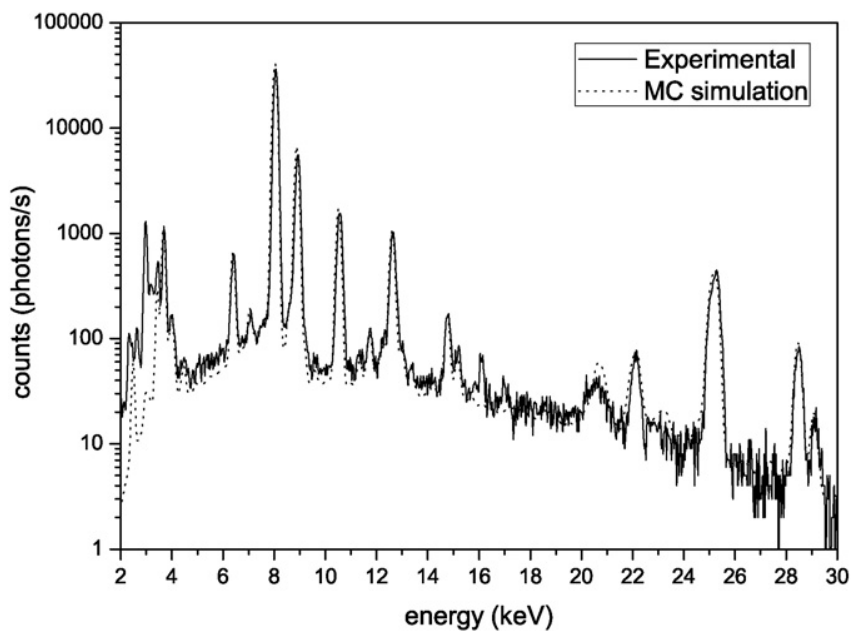

Fig. 4. Experimental and simulated spectra of one of the shafts.

layers: one $150 \mu \mathrm{m}$ thick and the other one virtually of infinite thickness, (from the point of view of X-Ray absorption). The thin layer resulted being composed by a Paraloid-like varnish applied in past conservation treatments. The estimate of its thickness is essentially based on the simulation of the background region of the spectrum, inasmuch as a thinner layer will produce a low intensity background, while a thicker one will decrease the peak intensities, especially those at lower energies. The simulated bronze layer composition gave the following values: $90 \mathrm{wt} \%$ of copper, $1.5 \%$ of iron, $0.3 \%$ of silver, $6.0 \%$ of tin and $4.0 \%$ of lead.

In Fig. 3b, a spot from a lateral area of the basket is reported, together with the simulation spectrum. The model used for the simulation is the same as the one used for Fig. 3a, but, in this case, the simulation displaying the best fit produced a different values: $86 \%$ of copper, $1.5 \%$ of iron, $0.3 \%$ of silver, $8 \%$ of tin and $6.0 \%$ of lead. The higher tin and lead contents can be explained by the position of the sample mold during casting and by the different fluidity, i.e. mobility, of the elements composing the alloy.

In Fig. 4, the experimental and simulated spectra from one of the shafts are reported. In this case, the sample geometry is quite different. It is formed by two coaxial cylinders, the external one $170 \mu \mathrm{m}$ thick and the internal one equivalent to infinite thickness. The composition is equal to the one corresponding to the bottom part of the basket. We have tried to simulate the shafts as flat surfaces but the simulated spectrum displayed a worse fit compared with the one obtained by assuming a cylindrical shape. A brief explanation of the criteria used in the

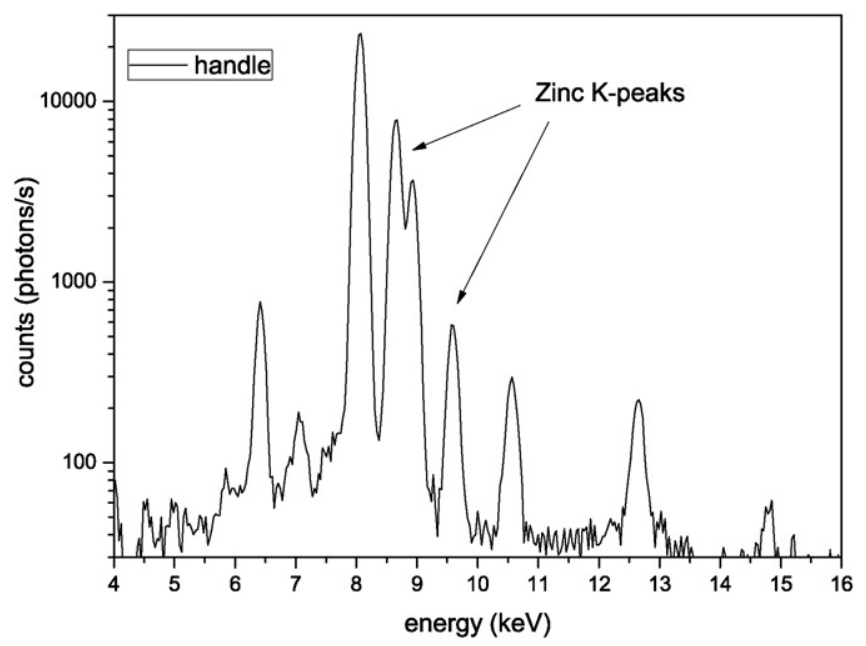

Fig. 5. Experimental and simulated spectra of one of the handles. It is clearly visible the Zinc K-line peaks. 


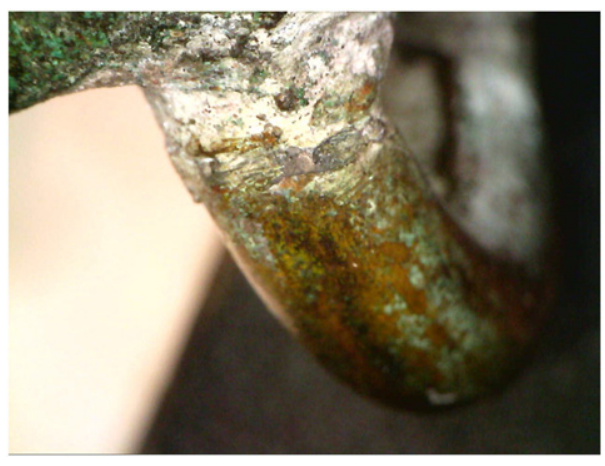

Fig. 6. Handle base magnified.

selection of the geometrical model to introduce in the simulation test is as follows: any surface can be modeled as a flat one if the size of the $\mathrm{x}$ ray beam is small enough with respect to the surface curvature. However, in the case studied here, we have another constraint, i.e. surface roughness. In order to minimize its influence on the measured spectrum, we need to use a relatively large beam. The beam impinging on the surface has a equivalent surface of about $10 \mathrm{~mm}^{2}$ and this size is comparable with the shaft size.

Lastly, in Fig. 5, the experimental spectrum of one area on the handles (see Figs. 1 and 6) has produced a very surprising result because the measurements show that it is clearly formed by brass (as evidenced by the large zinc peak in the spectrum, Fig. 6). This means that the handles most surely represent a later addition to the original artifact. It can be also noticed in Fig. 5, where traces of welding are visible together with a peculiar rhomboidal net incised on the surface. This finding came as a great surprise as it remained unnoticed to archeologists and conservators for the last three centuries. In fact, a thorough research discovered an additional drawing made just a few decades before the one reported in Fig. 1a where the basket is absent. Probably the restorer of the XVI century thought that the right position of the basket was on the head and to fix it in that position, he added two brass handles.

\section{Conclusion}

A unique nuragic bronze has been analyzed for the first time by combining XRF Spectroscopy with Monte Carlo simulations. Besides bronze characterization, a forgery has also been detected. The approach used here allows to obtain a better estimate of the bronze bulk chemical composition and even to detect the presence of protective layers applied in past conservation interventions, such as the Paraloid one encountered in this study, normally "invisible" by XRF analysis alone. It is fast enough to obtain a good estimate in less than $1 \mathrm{~h}$ depending on the geometrical and compositional complexity of the sample. Future research will focus on to development of an automatic procedure for the Montecarlo simulations.

\section{Acknowledgments}

This work has been partially supported by L.R. 7 of Regione Sardegna Italy (project n. J71J12000530007).

\section{References}

[1] J.-J. Barthélemy, Mémoire sur les anciens monuments de Rome, in Mémoires de l'Académie des Inscriptions et Belles-Lettres XXVIII, 1755-1757, 1761 579-610 (in french).

[2] G. Pinza, Monumenti primitivi della Sardegna, in MonAnt XI, coll, 1901 5-280 (in italian).

[3] J. Winckelmann, Geschichte der Kunst des Alterthums, I, 1776 (in german).

[4] A.M. Cardeira, S. Longelin, A. Le Gac, I. Nogueira, M.L. Carvalho, M. Manso, Spectroscopic characterization of a contemporary Indian miniature painting, Appl. Spectrosc. 67 (2013) 1376-1381.

[5] M. Manso, S. Pessanha, F. Figueira, S. Valadas, A. Guilherme, M. Afonso, A.C. Rocha, M.J. Oliveira, I. Ribeiro, M.L. Carvalho, Characterisation of foxing stains in eighteenth to nineteenth century drawings using non-destructive techniques, Anal. Bioanal. Chem. 395 (2009) 2029-2036.

[6] M. Manso, M. Costa, M.L. Carvalho, X-ray fluorescence spectrometry on paper characterization: case study on XVIII and XIX century documents, Spectroch. Acta B 63 (2008) 1320-1323.

[7] R. Cesareo, A. Castellano, G. Buccolieri, S. Quarta, M. Marabelli, P. Santopadre, M. Leole, A. Brunetti, Portable equipment for energy dispersive X-ray fluorescence analysis of Giotto's frescoes in the chapel of the Scrovegni, Nuclear Instruments and Methods in Physics Research, Section B: Beam Interactions with Materials and Atoms 213 (2004) 703-706.

[8] R. Cesareo, C. Calza, M. Dos Anjos, R.T. Lopes, A. Bustamante, S.J. Fabian, W. Alva, Z.L.R. Chero, Pre-Columbian alloys from the royal tombs of Sipan; energy dispersive X-ray fluorescence analysis with a portable equipment, Appl. Radiat. Isot. 68 (2010) 525-528.

[9] J. Sherman, The theoretical derivation of fluorescent X-ray intensities from mixtures, Spectrochim. Acta 7 (1965) 283-306.

[10] T. Shiraiwa, N. Fujino, Theoretical calculation of fluorescent X-ray intensities in fluorescent X-ray spectrochemical analysis, Jpn. J. Appl. Phys. 5 (1966) 886-899.

[11] M. Mantler, X-ray fluorescence analysis of multiple-layer films, Anal. Chim. Acta 188 (1986) 25-35.

[12] D.K.G. De Boer, Calculation of X-ray fluorescence intensities from bulk and multilayer samples, X-Ray Spectrom. 19 (1990) 145-154.

[13] R. Cesareo, A. Brunetti, S. Ridolfi, Pigment layers and precious metal sheets by energy-dispersive X-ray fluorescence analysis, X-Ray Spectrom. 37 (2008) 309-316.

[14] R. Cesareo, M.A. Rizzutto, A. Brunetti, D.V. Rao, Metal location and thickness in a multilayered sheet by measuring $\mathrm{K} \alpha / \mathrm{K} \beta, \mathrm{L} \alpha / \mathrm{L} \beta$ and $\mathrm{L} \alpha / \mathrm{L} \gamma$ X-ray ratios, Nucl. Instrum. Methods Phys. Res., B 267 (17) (2009) 2890-2896.

[15] R. Cesareo, A. Brunetti, Metal sheets thickness determined by energy-dispersive Xray fluorescence analysis, J. X-ray Sci. Technol. 16 (2008) 119-130.

[16] T. Schoonjans, L. Vincze, V.A. Solé, M. Sanchez del Rio, P. Brondeel, G. Silversmit, K. Appel, C. Ferrero, A general Monte Carlo simulation of energy-dispersive X-ray fluorescence spectrometers - Part 5. Polarized radiation, stratified samples, cascade effects, M-lines, Spectrochim. Acta B 70 (2012) 10-23.

[17] L. Vincze, K. Jansssens, F. Adams, A general Monte Carlo simulation of energydispersive X-ray fluorescence spectrometers-I. Unpolarized radiation, homogeneous samples, Spectrochim. Acta B 48 (1993) 553-573.

[18] U. Bottigli, A. Brunetti, B. Golosio, P. Oliva, S. Stumbo, L. Vincze, P. Randaccio, P. Bleuet, A. Simionovici, A. Somogyi, Voxel-based Monte Carlo simulation of X-ray imaging and spectroscopy experiments, Spectrochim. Acta B 59 (2004) 1747-1754.

[19] B. Golosio, T. Schoonjans, A. Brunetti, P. Oliva, G.L. Masala, Monte Carlo simulation of $\mathrm{x}$-ray imaging and spectroscopy experiments using quadric geometry and variance reduction techniques, Comput. Phys. Commun. 185 (2014) 1044-1052.

[20] A. Brunetti, B. Golosio, A new Monte Carlo code for simulation of the effect of irregular surfaces on X-ray spectra, Spectrochim. Acta Part B 94 (2014) 58-62.

[21] A. Brunetti, M. Sanchez del Rio, B. Golosio, A. Simionovici, A. Somogyi, A library for X-ray-matter interaction cross sections for X-ray fluorescence applications, Spectrochim. Acta B 59 (2004) 1725-1731.

[22] T. Schoonjans, A. Brunetti, B. Golosio, M. Sanchez del Rio, V.A. Solé, C. Ferrero, L. Vincze, The xraylib library for X-ray-matter interactions. Recent developments, Spectrochim. Acta B 66 (2011) 776-784.

[23] M. Manso, N. Schiavon, I. Queralt, A.M. Arruda, J.M. Sampaio, A. Brunetti, Alloy characterization of a 7th century BC archaeological bronze vase - overcoming patina constraints using Monte Carlo simulations, Spectrochim. Acta B 107 (2015) 93-96, http://dx.doi.org/10.1016/j.sab.2015.03.001.

[24] N. Schiavon, A. Celauro, M. Manso, A. Brunetti, F. Susanna, Early Iron Age bronze statuettes in Southern Portugal: combining archaeological data with EDXRF and BSEM + EDS to assess provenance and production technology, Appl. Phys. A 113 (4) (2013) 865-875, http://dx.doi.org/10.1007/s00339-013-7747-7. 